\title{
CRIOPRESERVAÇÃO DO SÊMEN OVINO EM PELLETS COM ETILENO GLICOL ${ }^{1}$
}

\author{
ETHYLENE GLYCOL FOR FREEZING RAM SEMEN IN PELLETS
}

\section{Cácio do Nascimento Moraes ${ }^{2}$ Jairo Pereira Neves ${ }^{3}$ Paulo Bayard Dias Gonçalves $^{3}$ João Francisco Coelho de Oliveira ${ }^{4}$ Cristine Marie Schweitzer $^{2}$}

\section{RESUMO}

Com a finalidade de avaliar a eficácia do etileno glicol para a preservação do sêmen ovino, utilizou-se 16 pools de sêmen, sendo cada um dividido em quatro aliquotas com concentrações de $0,3 \mathrm{M}, 0,5 \mathrm{M}$ e $0,7 \mathrm{M}$ de etileno glicol para comparação com $0,72 \mathrm{M}$ de glicerol. A avaliação do sêmen por teste de termo-resistência demonstrou que a motilidade inicial, final e vigor final foram semelhantes para $0.5 \mathrm{M}$ de etileno glicol e $0.72 \mathrm{M}$ de glicerol, $e$ superiores aos demais tratamentos. No entanto, o grupo que utilizou - etileno glicol em 0,5M proporcionou uma melhor proteção acrossomática. Setenta ovelhas divididas em três grupos (etileno glicol 0,5M, glicerol 0,72M e sêmen fresco), foram submetidas a sincronização de cios, inseminação, pela via cervical e diagnóstico de gestação aos 45 dias de gestação por ultra-sonografia. Não foram observadas diferenças significativas entre o grupo do etileno glicol com os do sêmen fresco e glicerol, porém verificou-se diferença entre os grupos do sêmen fresco e do glicerol. Considerando os resultados obtidos, conclui-se que o etileno glicol utilizado na concentração de 0,5M propicia motilidade e vigor semelhantes ao glicerol $(0,72 M)$, porém proporciona uma melhor proteção acrossomática.

Palavras-chave: etileno glicol, congelação sêmen, ovinos

\section{SUMMARY}

The aim of the present study was to verify the efficiency of ethylene glycol for freezing ram semen. A total of 16 pools of semen was used and each pool was divided in four fractions, which were frozen with ethylene glycol (in concentration of $0.3 \mathrm{M}, 0.5 \mathrm{M}$ or $0.7 M)$ or glycerol $(0.72 M$; control group $)$. The percentage of motile spermatozoa after thawing (initial motility) and after 5 hour of incubation at $37 \mathrm{C}$ (final motility) as well as the final sperm vigor were similar after freezing with ethylene glycol (0.5M) and glycerol (0.72M). The other concentrations of ethylene glycol resulted in lower sperm motility and vigor. However, ethylene glycol, in the concentration of $0.5 \mathrm{M}$, was able to increase the number of sperm with intact acrosomes. Seventy ewes were divided into three different treatments (ethylene glycol-0.5M, glycerol-0.72M and fresh semen). The estrous were synchronized and the ewes were inseminated by cervical technique. Forty-five days after finishing the artificial insemination program, pregnancy diagnosis was performed by ultrasound. The pregnancy rate was similar when the ethylene glycol treatment group was compared to the glycerol and fresh semen. However, the percentage of pregnancy was higher in the group of ewes inseminated with fresh semen than with semen frozen with glycerol ( $p<0.0003)$. Considering these results, we can conclude that ethylene glycol in a concentration of $0.5 \mathrm{M}$ is efficient for freezing ram semen, allowing post-thaw sperm motility similar to glycerol (0.72M) but with higher number of intact acrosomes.

Key words: ethylene glycol. frozen semen, sheep.

\section{INTRODUÇÃo}

A melhoria da qualidade do sêmen ovino congelado tem sido motivo de muitas pesquisas, visando o aumento dos índices de nascimento de ovelhas inseminadas pela via cervical. Esta técnica torna o emprego do sêmen mais acessível, reduzindo

\footnotetext{
${ }^{1}$ Trabalho realizado com suporte financeiro da FAPERGS.

${ }^{2}$ Médico Veterinário, MSc, autônomo, Lages, SC.

3

3 Professor Titular, Doutor, Departamento de Clínica de Grandes Animais, Centro de Ciências Rurais (CCR), Univesidade Federal de Santa Maria (UFSM), Santa Maria, RS, 97015-900, e-mail: jpneves@lince.hcv.ufsm.br. J.P. Neves: autor para correspondência.

${ }^{4}$ Professor Assistente, MSc, Depto de Clínica de Grandes Animais, CCR, UFSM, Santa Maria, RS. Recebido para publicação em 17.09.97. Aprovado em 22.10.97
} 
os custos e a necessidade de mão-de-obra especializada requeridas pela inseminação intra-uterina utilizando a laparoscopia. A partir da utilização do glicerol como crioprotetor, as pesquisas sobre congelação de sêmen tiveram um grande avanço, porém na espécie ovina o sêmen congelado utilizado pela via cervical ainda não proporciona resultados satisfatórios, devido a alterações bioquímicas e moleculares espermáticas ocorridas durante o processo de congelação e descongelação, redução do tempo de sobrevivência e falha de transporte após deposição no sistema genital da ovelha.

A criopreservação atinge diretamente a membrana plasmática dos espermatozóides, nas interações entre seus componentes através da influência das diversas etapas de resfriamento, congelação e descongelação (PARKS \& GRAHAM, 1992). A origem do comprometimento permanece incerta, mas algumas evidências sugerem que a membrana espermática fica afetada no reordenamento lipídico desde o resfriamento até o reaquecimento, desorganizando as associações lipo-proteicas, as quais são indispensáveis para o seu funcionamento. As membranas celulares, incluindo a dos espermatozóides, também são afetadas durante a congelação e descongelação, através da adição do crioprotetor, das alterações volumétricas, associadas a distensão e contração em resposta a soluções hiperosmóticas, da desidratação induzida pela congelação, da elevada concentração de solutos e da formação de gelo intracelular (WEITZE \& PETZOLDT, 1992).

A congelação e a descongelação do sêmen determinam marcadas alterações na estrutura da membrana, redução do transporte espermático e sua viabilidade no sistema genital das ovelhas (MATTNER et al, 1969; LIGHTFOOT \& SALAMON, 1970; VALCÁRCEL et al., 1994). Após a descongelação, o percentual de membranas íntegras fica reduzido em $70 \%$ e foi encontrada uma correlação positiva entre este percentual de membranas integras imediatamente após a descongelação e a motilidade após 8 horas de incubação a $37^{\circ} \mathrm{C}$ (VALCÁRCEL et al. 1994). Outros autores consideram que somente 10 a $20 \%$ das células espermáticas continuam competentes para a fecundação, após a descongelação. Isto tem sido sustentado através de experimentos comparativos, utilizando inseminações com sêmen fresco e congelado (SALAMON \& MAXWELL, 1995b).

Os crioprotetores podem ser classificados em intracelulares, constituídos de moléculas pequenas requerendo maior concentração e extracelulares, constituídos de moléculas grandes e que requerem uma menor concentração para que protejam as células contra as crioinjúrias (MERYMAN, 1971). O glicerol, o DMSO (dimetil sufóxido), o 1,2-propanodiol e o etileno glicol, são intracelulares. Os extracelulares são constituídos de grandes moléculas de açúcar como a sacarose, rafinose, proteinas e liproteínas contidas no leite, gema de ovo e soro sangüíneo (RODRIGUES, 1992).

O glicerol é conhecido como protetor contra danos durante a criopreservação (POLGE et al. 1949), e a sobrevivência dos espermatozóides em baixas temperaturas depende de sua concentração no meio (JONES, 1969; COLAS, 1975; WATSON \& MARTIN, 1975; NEVES, 1980; JOSHI, 1990). O mecanismo pelo qual ele protege as células não está completamente esclarecido. A hipótese mais provável é que sua ação mais efetiva ocorra ao nível extracelular (AMANN \& PICKETT, 1987) sendo possível a congelação do sêmen ovino logo após a sua adição (MATOS et al., 1992). Contrariamente, BERNDTSON \& FOOTE (1972) sugerem que ocorra uma rápida penetração do glicerol nos espermatozóides. A presença de glicerol durante a congelação diminui a concentração de sais no interior do espermatozóide, esperando-se com isso que ele auxilie na estabilização da membrana plasmática, pois esta alta concentração é nociva a membrana (HOLT et al. 1992).

O etileno glicol é um crioprotetor que despertou interesse para a congelação do sêmen ovino e quando utilizado na concentração de $1,5 \%$ e $2,0 \%$ mostrou-se semelhante ao glicerol $(3,5 \%)$. A fertilidade do sêmen congelado em meio composto de citrato, lactose e gema de ovo com $1,75 \%$ de etileno glicol ou 3,5\% de glicerol foi de $22 \%$, para ambos os tratamentos (PLATOV, 1965). Quando utilizado na concentração de $5 \%$ foi inferior ao glicerol $(5 \%)$. O sêmen congelado em pellets utilizando $1,75 \%$ e 3,5\% de etileno glicol teve melhor resultado que o glicerol em iguais concentrações, porém a concentração de etileno glicol que melhor protege os espermatozóides foi de 1,5\% (SALAMON \& MAXWELL, 1995a). A utilização do sêmen eqüino propiciou resultados semelhantes ao glicerol, quanto a motilidade e vigor, no entanto os índices de prenhez foram melhores quando foi utilizado o etileno glicol (MERCANTE et al, 1995; NEVES NETO et al, 1995). Atualmente os estudos com etileno glicol tem se concentrado no âmbito da criopreservação de embriões, permitindo bons resultados de prenhez e facilitando a descongelação (VOELKEL, 1992ab; VISINTIN et al, 1995ab). Este trabalho foi desenvolvido com o objetivo de avaliar a eficácia do etileno glicol para preservação do sêmen ovino. 


\section{MATERIAIS E MÉTOdos}

Utilizaram-se três cameiros da raça Ile de France e um da 3/4 Romney Marsh + 1/4 Merino Booroola, todos com 3 anos de idade, em bom estado nutricional e aptos para a reprodução. Durante os experimentos, os animais foram mantidos em estábulos individuais num regime de semi-confinamento $e$ submetidos a um regime de duas coletas de sêmen por dia, duas vezes por semana. Os ejaculados, para formação de um "pool", foram obtidos com vagina artificial e colocados em banho-maria à $30^{\circ} \mathrm{C}$, sendo avaliados quanto ao volume (ml), turbilhão (1-3 cruzes), motilidade (\%), vigor (1-5) e concentração espermática. Procedeu-se também a tomada de uma amostra de sêmen para avaliação da morfologia espermática.

Foram utilizados somente os ejaculados com os seguintes padrões mínimos: volume $0,5 \mathrm{~m}$, turbilhão nivel 2 , motilidade de $65 \%$, concentração de $3 \times 10^{6} / \mathrm{mm}^{3}$ (cremoso fino) e $80 \%$ de espermatozóides morfologicamente normais. A avaliação da integridade de acrossomo e da morfologia espermática foram realizadas em preparação úmida em microscópio de contraste de fase (1000x). Foram contados um total de 100 espermatozóides por amostra. As demais avaliações foram realizadas em microscópio com iluminação convencional.

O congelamento do sêmen foi em pellets, com volume de 130 $\ell$, correspondendo a uma concentração mínima de $100 \times 10^{6}$ espermatozóides $/ \mathrm{mm}^{3}$, a partir da diluição de uma parte de sêmen para três partes de diluente, conforme técnica desenvolvida por EVANS \& MAXWELL (1987). A congelação do sêmen foi realizada em placa de acrílico de $4 \mathrm{~mm}$ de espessura a uma distância de $3 \mathrm{~cm}$ acima do nível do nitrogênio líquido.

Para os estudos in vitro, foram constituídos quatro grupos, conforme o crioprotetor utilizado e sua concentração. Cada pool de sêmen, constituído por quatro ejaculados dos diferentes carneiros utilizados, foi dividido em quatro alíquotas, as quais foram diluídas com solução estoque adicionada do crioprotetor $(0,3 \mathrm{M}, 0,5 \mathrm{M}$ ou $0,7 \mathrm{M}$ de etileno glicol ou $0,72 \mathrm{M}$ de glicerol - grupo controle). A solução estoque foi composta de $3,87 \mathrm{~g}$ de Tris (Hydroximethil) aminometano; $0,533 \mathrm{~g}$ de glicose; $2,123 \mathrm{~g}$ de ácido cítrico; 16me de gema de ovo; 100.000 Ul de penicilina; $100 \mathrm{mg}$ de estreptomicina; água tri-destilada e deionizada até $100 \mathrm{~m} \ell$ (EVANS \& MAXWELL,1987). Cada pellet foi constituído com uma concentração mínima de 100 milhões de espermatozóides.
A descongelação do sêmen ocorreu sempre 24 horas após sua congelação, em banho-maria $37^{\circ} \mathrm{C}$, em um tubo de ensaio contendo $0,39 \mathrm{~m} \ell$ de citrado de sódio a $2,94 \%$, com o cuidado de agitar o tubo até o completo descongelamento. Foram avaliadas a motilidade e o vigor logo após o descongelamento e após 5 horas de incubação, assim como a morfologia do acrossomo logo após a descongelação.

Para a inseminação artificial foram utilizadas 70 ovelhas da raça Ideal com idade entre 2 e 3 anos, as quais tiveram ciclo sincronizado com esponjas intra-vaginais (50mg de acetato de progesterona) e ovulação induzida com eCG (500UI) aplicado via intramuscular. Utilizou-se sêmen criopreservado com etileno glicol $(0,5 \mathrm{M})$ ou glicerol $(0,72 \mathrm{M})$ por deposição cervical superficial utilizando uma pipeta de vidro (EVANS \& MAXWELL, 1987), na qual foi acoplada uma seringa para aspiração e deposição do sêmen. Cada dose de sêmen continha um mínimo de de $200 \times 10^{6}$ de espermatozóides, correspondendo a dois pellets. O sêmen fresco foi obtido com vagina artificial, avaliado e mantido à $30^{\circ} \mathrm{C}$ até o momento de sua aplicação. A inseminação foi realizada em média 12 horas após detecção do cio, mediante a deposição cervical superficial.

$\mathrm{O}$ experimento foi desenvolvido em blocos inteiramente casualizados, sendo que cada "pool" de sêmen utilizado no experimento $(n=16)$ foi considerado um bloco. Tendo em vista que os resultados obtidos foram em percentagem, os dados foram transformados pelo PROC RANK no programa estatístico SAS (1988), para usar um modelo de análise estatística paramétrico. Os resultados encontrados nos diferentes tratamentos foram comparados usando o seguinte modelo aditivo para o delineamento experimental em blocos casualizados:

$$
\mathrm{Y}_{\mathrm{ijk}}=\mu+\alpha_{\mathrm{i}}+\beta_{\mathrm{j}}+\varepsilon_{\mathrm{ijk}}
$$

onde $Y_{i j k}$ foram as percentagens transformadas obtidas pelos tratamentos nos diferentes experimentos, $\mu$ foi a constante comum a todas as observações, $\alpha$ foram os efeitos dos tratamentos, $\beta_{\mathrm{j}}$ foram os efeitos dos blocos, e $\varepsilon_{i j \mathrm{k}}$ foi o efeito residual. As médias foram comparadas pelo contraste do método dos mínimos quadrados ponderados no PROC GLM (SAS, 1988).

As percentagens de prenhez obtidas com sêmen fresco, congelado com glicerol ou etileno glicol foram analizadas por qui-quadrado. Os resultados dos tratamentos foram comparados utilizando a análise de contraste no PROC CATMOD (SAS, 1988). 


\section{RESULTADOS E DISCUSSÃO}

Na Tabela 1 estão expressos os valores de motilidade e vigor logo após o descongelação, no final do teste de termo-resistência lento, assim como o percentual de acrossomos alterados imediatamente após o descongelação. A concentração de etileno glicol de $0,5 \mathrm{M}$ propocionou os melhores resultados, pois além da mesma motilidade espermática observada no grupo controle (glicerol), proporcionou uma melhor proteção acrossomática. Os grupos do glicerol e 0,7M de etileno glicol caracterizaram-se por uma alta percentagem de alterações de acrossomo, diferindo $(\mathrm{P}<0,05)$ das outras duas concentrações de etileno glicol. Tanto a motilidade como o vigor, observados nos diferentes momentos de avaliação espermática, não apresentaram diferenças $(\mathrm{P}>0,05)$ entre os grupos do glicerol e de $0,5 \mathrm{M}$ de etileno glicol.

Os resultados indicaram que $0,5 \mathrm{M}$ de etileno glicol foi capaz de manter uma motilidade inicial semelhante a do glicerol $(\mathrm{P}=0,443)$ e promover uma melhor proteção do acrossomo $(\mathrm{P}<0,0001)$, indicando que a sua capacidade de crioproteção foi superior a do glicerol. O etileno glicol $(0,3 \mathrm{M})$ representa $1,7 \%$ do diluente, fícando na concentração considerada por SALAMON \& MAXWELL (1995a) a ideal. Neste experimento, a utilização de $0,3 \mathrm{M}$ proporcionou os melhores percentuais de preservação acrossomática, porém não diferiu de $0,5 \mathrm{M}(\mathrm{P}>0,146)$, que mostrou-se superior em motilidade inicial $(P>0,0001)$ e ao final do período de incubação $(P>0,0001)$, sendo o mesmo efeito observado no vigor. Quando o etileno glicol foi utilizado na maior concentração $(0,7 \mathrm{M}=3,9 \%)$, apresentou o pior desempenho, tanto em motiilidade e vigor, quanto em alterações de acrossomo. Outros experimentos comparando glicerol e etileno glicol em concentrações idênticas $(5 \%)$, demonstraram uma superioridade do glicerol (SALAMON, 1968). Resultados similares foram observados neste experimento, onde foi encontrada uma diminuição significativa da efíciência do etileno glicol, na maioria dos parâmetros estudados, quando as concentrações foram superiores a $0,5 \mathrm{M}$ $(2,8 \%)$. Assim, pode-se determinar que são necessárias menores concentrações de etileno glicol do que de glicerol para obter índices ideais de criopreservação do sêmen ovino. A propriedade do etileno glicol em melhor preservar o acrossomo, pode significar também uma melhor preservação de outras estruturas dos espermatozóides, como o núcleo, cuja integridade é indispensável para que ocorra um perfeito desenvolvimento embrionário e que a gestação chegue a termo. Isto pode explicar porque em equinos, onde o glicerol e o etileno glicol foram semelhantes em motilidade e vigor, houve superioridade em prenhez quando o crioprotetor utilizado foi o etileno glicol (MERCANTE $\boldsymbol{e} \boldsymbol{t} \boldsymbol{a} \boldsymbol{l} .1$ 1995; NEVES NETO $\boldsymbol{e} \boldsymbol{t} \boldsymbol{a l}$. 1995). Este fato é importante, pois a utilização de sêmen congelado na espécie ovina proporciona uma maior perda embrionária (MIES FILHO, 1987; MORAES, 1992)

A melhor proteção do acrossomo com a utilização do etileno glicol $(0,5 \mathrm{M})$, pode ser explicada pela sua velocidade de penetração. $\mathrm{O}$ etileno glicol penetra mais rápido na célula, o que poderá proporcionar uma diminuição da alta concentração de sais no interior do espermatozóide. Esta alta concentração de sais é nociva a membrana espermática

(HOLT et al. 1992). Os efeitos do glicerol sobre o espermatozóide tem sido motivo de várias pesquisas, porém ainda não se conseguiu bons índices de nascimento de cordeiros em programas de inseminação cervical, utilizando este crioprotetor com os atuais diluentes. $\mathrm{O}$ potencial do etileno glicol em melhor proteger a membrana celular faz acreditar que com esse crioprotetor as chances em obter sucesso através da inseminação cervical são maiores, pois permitiria uma maior sobrevivência espermática, considerando as correlações já estudadas sobre 
integridade de acrossomo e motilidade espermática (BARNABE et al. 1981).

A inseminação artificial serviu de um indicativo de que o etileno glicol $(0,5 \mathrm{M})$ pode proporcionar melhores resultados que o glicerol na inseminação cervical ovina, como mostra a Figura 1. No entanto, esta tecnologia ainda é um desafio, pela complexidade do assunto, onde a verdadeira causa da instabilidade dos resultados não esta bem definida, ou seja, se ela tem origem na manipulação do sêmen doado pelo macho, na complexa estrutura cervical, no transporte espermático na fêmea ou associação destes fatores. O etileno glicol $(0,5 \mathrm{M})$ propiciou melhores resultados que o glicerol $(0,72 \mathrm{M})$, principalmente no que se refere a preservação do acrossomo, estrutura indispensável no momento de fecundação.

Conclui-se que o sêmen ovino pode ser congelado utilizando como crioprotetor o etileno glicol, que quando utilizado na concentração de $0,5 \mathrm{M}$ proporciona motilidade e vigor semelhantes a do glicerol, porém com uma melhor proteção acrossomática.

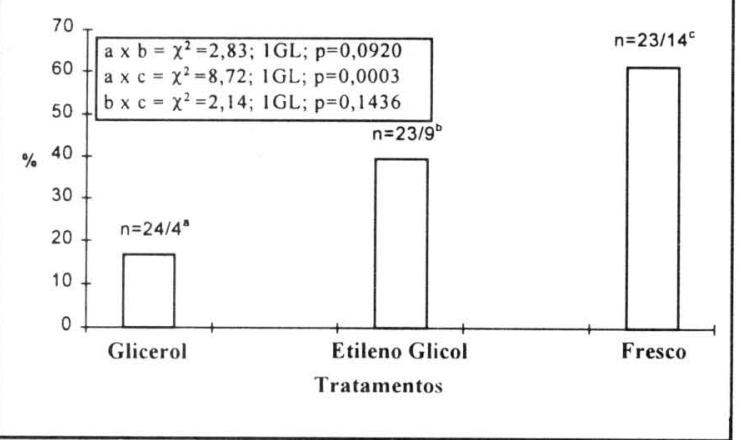

Figura 1 - Efeito de dois crioprotetores em comparação com o sêmen fresco na percentagem de prenhez de ovelhas inseminadas pela via cervical superficial.

\section{REFERÊNCIAS BIBLIOGRÁFICAS}

AMANN, R.P., PICKETT, B.W. Principales of cryopreservation and a review of stallion spermatozoa. Equine Vet Sci, v. 7, p $145-173,1987$

BARNABE, V.H., BARNABE, R.C., VISINTIN, J.A.; et. al Correlaçðes entre motilidade progressiva e retenção do acrossomo em sêmen congelado de bovinos após o descongelamento e após provas de termoresistência. Rev Fac Med Vet Zootec Univ de São Paulo, v. 18, p. 61-68, 1981.

BERNDTSON, W.E., FOOTE, R.H. Bovine sperm cell volume at various intervals after addition of glycerol at $5{ }^{\circ} \mathrm{C}$. Cryobiology, v. 9 , p. $57-60,1972$.

COLAS, G. Effect of initial freezing temperature, addition of glycerol and dilution on the survival and fertilizing ability of deep-frozen ram semen. J Reprod Fert, v. 42, p. 277-285, 1975.

EVANS,G., MAXWELL, W.M.C. Salamon's artificial insemination of sheep and goats. Sydney, Butterworths, 1987 $194 \mathrm{p}$.

HOLT, W.V.; HEAD, M.F.; NORTH, R.D. Freeze-induced membrane in ram spermatozoa is manifested after thawing. observations with experimental cryomicroscopy. Biol Reprod, v. 43, p. 1086-1094, 1992.

JONES, R.C. Studies of the suitability of preparations of ewe and cow milk for storing ram spermatozoa at 375 and $-79^{\circ} \mathrm{C}$. Aust J Biol Sci, v. 22, p. 983-900, 1969.

JOSHI, A. Factors affecting metabolic behaviour of ram spermatozoa during cryopreservation. Indian J Anim Sci, v 60, p. 1336-1337, 1990.

LIGHTFOOT, R.J., SALAMON, S. Freezing ram spermatozoa by the pellet method. I. Transport and viability of spermatozoa within the genital tract of the ewe. J Reprod Fert, v. 22, p. 385-398, 1970.

MATOS, D.G., MOSES, D.F., de las HERAS, M.A., et al. Minimal time required in contact with glyce rol for cryopreservation of ram semen. In: INTERNATIONAL. CONGRESS. ON ANIMAL. REPRODUCTION, 12, 1992, The Hague. Proc.. The Hague: International Congress on Animal Reproduction, 1992, v. 3, p. 1401-1403

MATTNER, P.E., ENTWISTLE, K.N., MAR TIN, I.C.A. Passage survival and fertility of deep frozen ram semen in the genital tract of the ewe. Aust J Biol Sci, v. 22, p. 181-187, 1969.

MERCANTE, C.F.J., ARRUDA, R.P., NEVES NETO, J.R.,et al. Congelação de sêmen equino em etilenoglicol ou glicerol motilidade, vigor e teste de termorresistência. In: CONGRESSO BRASILẸIRO DE REPRODUÇÃO ANIMAL, 1995. Anais... Belo Horizonte, MG: Congresso Brasileiro de Reprodução Animal, 1995, p. 290

MERYMAN, H.T. Crioprotective a gents. Cryobiology, v. 8, p $173-183,1971$

MIES FILHO, A. Inseminação Artificial. 6. ed., Porto Alegre Sulina, 1987. V. 2. $750 \mathrm{p}$

MORAES, J.C.F. A mortalidade embrionária e a eficácia da inseminação artificial em ovinos. Ciência Rural, v. 22, p. $367-$ 372,1992

NEVES, J.P. Untersuchungen zur Samenübertragung beim Schaf unter besondere Berücksichtigung der Spermatiefgefrierkonservierung. Hannover, Alemanha $107 \mathrm{p}$ Tese (Doutorado em Medicina Veterinária) Escola Superior de Veterinária de Hannover, Alemanha, 1980.

NEVES NETO, J.R., MERCANTE, C.F.J., ARRUDA, R.P., et al. Fertilidade do sêmen equino congelado com etilenoglicol ou glicerol. In: CONGRESSO BRASILEIRO DE REPRODUÇÃO ANIMAL,11, 1995, Belo Horizonte MG. Anais ... Minas Gerais: Congresso Brasileiro Reprodução Animal, 1995. p. 292.

PARKS, J.E. , GRAHAM, J.K. Effects of cryopreservation procedures on sperm membranes. Theriog, v. 38, p. 209-222, 1992. 
PLATOV, E.M. The freezing of ram semen in a lactose-yolk ethileneglycol diluent. An Breeding Abst, p. 76-77. 1965.

POLGE, C, SMITH, A.U., PARKES, A.S. Revival of spermatozoa after vitrification and dehydration at low temperatures. Nature, v. 164, p. $666-668,1949$.

RODRIGUES, J. L. Aspectos da congelação de embriões bovinos. In: REUNIÃO DA SOCIEDADE BRASILEIRA DE TRANS FERÊNCIA DE EMBRIÕES, 7, Jaboticabal, SP. Anais... Jaboticabal: Sociedade brasileira de transferência de embriões, 1992, p. 55-79.

SALAMON, S. Deep freezing of ram semen: recovery of spermatozoa after pelleting and comparison with other methods of freezing. Aust J Biol Sci, v. 21, p. 351-360, 1968.

SALAMON, S., MAXWELL, W.M.C. Fro zen storage of ram semen I. Processing, freezing, thawing and fertility after cervical insemination. An Reprod Sci, v. 37, p. 185-249, 1995a.

SALAMON, S., MAXWELL, W.M.C. Frozen storage of ram semen II. Causes of low fertility after cervical insemination and methods of improvement. An Reprod Sci, v. 38, p. 1-36, 1995 b.

SAS SAS/STAT USER'S GUIDE. 6.03 ed. Cary, NC, USA: SAS Institute INC, 1988. $1028 \mathrm{p}$.

VALCÁRCEL, A., DE LAS HERAS, M.A., PÉREZ, et al. Fluorescent staining as a method of assessing membrane damage and post-thaw survival of ram spermatozoa. Theriog, v. 41, p 483-489, 1994.

VISINTIN, J.A., GARCIA, J.F., NOGUEIRA, M.F.G., et al. Criopreservação de embriões bovinos micromanipulados e sexados, pelo método "one-step". In: I SIMPÓSIO BRASILEIRO DE PESQUISA EM MEDICINA VETERINÁRIA, São Paulo, SP. Anais...São Paulo, 1995a, p. 119.

VISINTIN, J.A., GARCIA, J.F., NOGUEIRA, M.F.G., et al Criopreservação de embriões bovinos: método "one-step". In: I SIMPÓSIO BRASILEIRO DE PESQUISA EM MEDICINA VETERINÁRIA, São Paulo, SP. Anais...São Paulo, 1995b, p. 120.

VOELKEL, S.A., HU, Y.X. Direct transfer of frozen-thawed bovine embryos. Theriog, v. 31, p. 23-37, 1992a.

VOELKEL, S.A, HU, Y.X. Use of ethylene glycol as a cryoprotectant for bovine embryos allowing direct transfer of frozen thawed embryos torecipient females. Theriog, v. 37, p. 687-697, 1992b.

WATSON, P.F., MARTIN, I.C.A. Effects of egg yolk, glycerol and the freezing rate on the viability and acrossomal structures of frozen ram spermatozoa. Aust J Biol Sci, v. 28, p. 153-159, 1975.

WEITZE, K.F. , PETZOLDT, R. Preservation of semen. Reprod Sci, v. 28 , p. $229-235,1992$.

Ciência Rural, v. 28, n. 2, 1998. 